\title{
Efeito de vitaminas adicionadas ao diluente ACP-104 sobre a qualidade do sêmen criopreservado de carpa comum (Cyprinus carpio)
}

\author{
[Effect of vitamins added to the ACP-104 extender on the quality of cryopreserved semen \\ of common carp (Cyprinus carpio)] \\ F.R.A. Linhares, M.S. Oliveira-Araújo, J.F. Nunes, M.A.M. Carvalho, \\ C.C. Campello, C.S.B. Salmito-Vanderley \\ Universidade Estadual do Ceará - UECE - Fortaleza, CE
}

\begin{abstract}
RESUMO
O objetivo da presente pesquisa foi alcançado com a divisão da pesquisa em dois experimentos: (1) aperfeiçoar o protocolo de congelação utilizando água de coco em pó (ACP-104) como diluente para a criopreservação seminal de carpa comum; (2) avaliar o efeito da suplementação das vitaminas C (ácido ascórbico) ou $\mathrm{E}$ ( $\alpha$-tocoferol) sobre os melhores diluidores testados no experimento 1 na qualidade do sêmen pós-descongelado da espécie. Para o experimento 1 , foram formados oito pools de sêmen, provenientes de 14 machos selecionados. As amostras seminais coletadas foram avaliadas quanto à motilidade total, à velocidade, ao percentual de espermatozoides normais e à vitalidade espermática antes e depois da criopreservação seminal. Esta foi realizada em meio ACP-104 acrescido de dimetilsulfóxido (DMSO), ou etilenoglicol (EG), ou glicerol, ou metanol, todos à concentração de 10\%, diluídos em 1:3 (sêmen:diluidor). As amostras foram, então, congeladas em vapor de nitrogênio líquido em dry shipper e estocadas em nitrogênio líquido $\left(-196^{\circ} \mathrm{C}\right)$. Para o experimento 2 , foram formados oito pools provenientes da coleta de sêmen de 15 machos. As amostras seminais foram avaliadas seguindo as mesmas análises do experimento 1, acrescentando-se a duração da motilidade total. A criopreservação seminal utilizou-se do meio ACP-104 acrescido de DMSO ou EG, suplementado ou não com vitamina C ou E. Os melhores resultados encontrados no experimento 1 foram obtidos com o DMSO e o EG. Estes não diferiram significativamente entre si para a motilidade total $(24 \%$ e $28 \% ; \mathrm{P}>0,05)$ e a normalidade espermática $(32 \%$ e $26 \%$; $>0,05)$, respectivamente. Para o experimento 2 , o EG suplementado com vitamina $E$ produziu significativamente resultados superiores de motilidade total, normalidade espermática e duração da motilidade em relação ao DMSO, concluindo-se que o EG deve ser, portanto, o crioprotetor de escolha a ser utilizado com o ACP-104 suplementado ou não com vitamina $\mathrm{E}$.
\end{abstract}

Palavras-chave: Cyprinus carpio, sêmen, criopreservação, antioxidantes, ACP-104

\begin{abstract}
The objective was achieved by dividing the research into two experiments: (1) improving the freezing protocol using powdered coconut water (ACP-104) as a diluent for the cryopreservation seminal of common carp; (2) evaluating the effect of supplementation of vitamins $C$ (ascorbic acid) or vitamin $E$ ( $\alpha$ tocoferol) with the best extenders tested in experiment 1 on the quality of post-thawed. For experiment 1 , semen pools from 14 selected males were formed. Seminal samples were evaluated for total motility, velocity, percentage of normal sperm and sperm vitality before and after the seminal cryopreservation. This was done in ACP-104 extender plus dimethyl sulfoxide (DMSO), or ethylene glycol (EG), or glycerol or methanol all at concentration 10\% diluted in 1:3 (semen:extender). The samples were frozen in vapors of nitrogen into dry shippers and stored in liquid nitrogen $\left(-196^{\circ} \mathrm{C}\right)$. For experiment 2 , eight pools were formed from the 15 males. The semen samples were evaluated following the same analysis of experiment 1 adding duration of total motility. The sperm cryopreservation was performed in extenders ACP-104 plus DMSO or EG supplemented or not with vitamin C or E. The best results found in Experiment 1 were
\end{abstract}

Recebido em 29 de julho 2016

Aceito em 8 de setembro de 2016

E-mail: renan.aragao@hotmail.com 
obtained with DMSO and EG. They do not differ significantly for total motility (24\% and 28\%; $P>0.05$ ) and normal sperm $(32 \%$ and $26 \%$; P>0.05) respectively. For experiment $2, E G$ supplemented with vitamin E, produced significantly better results overall motility, sperm normality and duration of motility relative to DMSO. In conclusion, EG should be the cryoprotectant of choice for use with the ACP-104 supplemented or not with vitamin $E$.

Keywords: Cyprinus carpio, sperm, cryopreservation, antioxidants, ACP-104

\section{INTRODUÇÃO}

$\mathrm{O}$ diluente ACP-104, preparado à base de água de coco, vem sendo utilizado com relativo sucesso na criopreservação do sêmen de peixes (Carvalho et al., 2014). No entanto, sua eficiência ainda é baixa como diluente para a criopreservação em termos de conservação da motilidade e de velocidades espermáticas, quando os resultados são comparados ao sêmen in natura (Linhares et al., 2015). Esse baixo desempenho tem sido observado em outros diluidores de criopreservação e foi correlacionado com os estresses térmico, osmótico e oxidativo (Li et al., 2010). Desse modo, são necessários novos estudos que possibilitem aumentar a eficiência do meio ACP104.

O estresse oxidativo é ocasionado pela geração excessiva de espécies reativas do metabolismo do oxigênio, conhecidas como ROS $\left(\mathrm{O}_{2}^{-}, \mathrm{OH}^{*}\right.$, $\mathrm{HO}_{2}{ }^{\circ}$ e $\mathrm{H}_{2} \mathrm{O}_{2}$ ) (Martinez-Páramo et al., 2012). As ROS podem prejudicar a função espermática; reduzir viabilidade, motilidade e integridade de membrana; aumentar a peroxidação lipídica e comprometer a atividade de algumas enzimas após criopreservação (Słowińska et al., 2013). Para combater a produção excessiva de ROS e o estresse oxidativo, o sêmen apresenta um sistema de defesa antioxidante intra e extracelular formado por componentes enzimáticos e não enzimáticos (Lahnsteiner e Mansour, 2010). No entanto, o sistema intracelular de defesa antioxidante do espermatozoide é mais susceptível à ação das ROS, devido à escassez de citoplasma, o qual é perdido durante a maturação celular (Carvalho et al., 2002). Alguns estudos têm demonstrado que a adição de antioxidantes aos meios de congelação de sêmen de peixes ajuda a proteger os espermatozoides, reduzindo os danos provocados pelo estresse oxidativo (Kutluyer et al., 2014; Navarro et al., 2014).

As vitaminas C (ácido ascórbico) e E ( $\alpha$ tocoferol e derivados) são antioxidantes não enzimáticos que protegem os espermatozoides de danos oxidativos do DNA e previnem a deterioração oxidativa de lipídios poliinsaturados presentes na membrana que rodeia as células $\mathrm{e}$ as organelas celulares (MartinezPáramo et al., 2012). Contudo, não existem publicações sobre a suplementação das vitaminas $\mathrm{C}$ ou $\mathrm{E}$ ao diluente ACP-104 quanto a sua capacidade de aumentar a qualidade seminal e proteger os espermatozoides de carpa comum do efeito tóxico dos radicais livres. Portanto, o objetivo da presente pesquisa foi otimizar o protocolo existente, definindo inicialmente qual crioprotetor deve ser usado em associação com o meio ACP-104 para a criopreservação seminal de carpa comum e posteriormente, após seleção do crioprotetor, avaliar o efeito da suplementação da vitamina $\mathrm{C}$ ou $\mathrm{E}$ ao diluidor escolhido sobre a qualidade do sêmen após a descongelação.

\section{MATERIAL E MÉTODOS}

A pesquisa foi aprovada pelo Comitê de Ética para o Uso de Animais da Universidade Estadual do Ceará (Ceua/UECE; 11516665-3/63). Os animais utilizados pertenciam ao Centro de Pesquisas em Aquicultura (CPAq) do Departamento Nacional de Obras Contra as Secas (DNOCS) (Pentecoste - Ceará).

A pesquisa foi dividida em dois experimentos: (1) aperfeiçoar o protocolo de congelação utilizando água de coco em pó (ACP-104) como diluente para a criopreservação seminal de carpa comum; (2) avaliar o efeito da suplementação das vitaminas $\mathrm{C}$ e $\mathrm{E}$ sobre os melhores crioprotetores selecionados no experimento 1 com base na qualidade do sêmen pósdescongelação. A coleta de sêmen foi realizada em janeiro de 2015. No primeiro experimento, o sêmen foi obtido de 14 machos sexualmente maduros $(46,36 \pm 3,63 \mathrm{~cm}$ e $1,68 \pm 0,41 \mathrm{~kg})$, que foram estimulados à espermiação após dose única de extrato hipofisário de carpa (EHC; Danúbio Aquicultura Ltda., Brasil) de $1 \mathrm{mg} / \mathrm{kg}$ de peso vivo. Os animais foram previamente 
sedados em solução de eugenol (Cequímica Ltda., Brasil), diluída em álcool absoluto e água (1:10:10000). Após 12 horas da indução hormonal, o sêmen foi coletado por meio de massagem abdominal, evitando-se contaminação com água, fezes, urina ou sangue. $\mathrm{O}$ sêmen foi coletado em tubos graduados, e as amostras conservadas em caixas térmicas $\left(\sim 5^{\circ} \mathrm{C}\right)$. $\mathrm{O}$ volume seminal $(\mathrm{mL})$ foi aferido diretamente nos tubos; o $\mathrm{pH}$, por meio de fitas de $\mathrm{pH}$ (MerckAlemanha); e a concentração espermática, por contagem em câmara de Neubauer. A análise subjetiva da motilidade foi estimada com o auxílio de um microscópio óptico (Nikon Eclipse E200 - ampliação de 100x) após a mistura de $2 \mu \mathrm{L}$ de sêmen e $100 \mu \mathrm{L}$ de água do tanque. Considerando-se como $\quad 0 \%$ nenhum espermatozoide móvel e como $100 \%$ todos os espermatozoides móveis, somente as amostras com motilidade superior a $80 \%$ foram utilizadas.

Por meio de amostras selecionadas, foram formados oito pools, cada um constituído pela combinação das amostras de três machos, de forma aleatória, com algumas outras carpas, contribuindo mais de uma vez para a formação dos pools. Cada pool foi dividido em quatro alíquotas, diluído na proporção de 1:3 (sêmen:diluidor) em diluente ACP-104 (ACP Biotecnologia, Fortaleza, Ceará, Brasil) e acrescido de dimetilsulfóxido (DMSO), etilenoglicol (EG), glicerol ou metanol, todos na concentração de 10\% (Cequímica Ltda., Brasil). Dessa forma, os quatro criodiluidores para cada pool foram: ACP-104 + DMSO; ACP-104 + EG; ACP-104 + glicerol e ACP-104 + metanol. O grupo controle correspondeu ao sêmen in natura. A solução crioprotetora foi preparada de acordo com Linhares et al. (2015).

No segundo experimento, verificou-se o efeito da suplementação com vitamina $\mathrm{C}$ ou $\mathrm{E}$ nos melhores criodiluentes do experimento 1 sobre a qualidade seminal. Para o sêmen obtido de 15 machos sexualmente maduros $(52,27 \pm 5,56 \mathrm{~cm}$; $2,37 \pm 0,80 \mathrm{~kg}$ ), seguiu-se o mesmo procedimento: indução hormonal, coleta e preparação das amostras, congelação e avaliação para ambos os experimentos. Cada pool $(\mathrm{n}=8)$ foi dividido em seis alíquotas e diluído na proporção de 1:3 (sêmen:diluidor) em diluente ACP-104 acrescido de $10 \%$ de DMSO ou EG suplementados ou não com vitamina $\mathrm{C}(0,0001 \mathrm{mg}$; ácido ascórbico) ou E $(0,0001 \mathrm{mg} ; \alpha$-tocoferol $)$, conforme Navarro et al. (2014). Assim, foram formados seis tratamentos: ACP-104 + DMSO; ACP-104 + $\mathrm{DMSO}+$ vitamina C; ACP-104 + DMSO + vitamina E; ACP-104 + EG; ACP-104 + EG + vitamina $\mathrm{C}$ e ACP-104 + EG + vitamina $\mathrm{E}$. O grupo controle correspondeu ao sêmen in natura.

A criopreservação seminal realizada nos dois experimentos seguiu a seguinte metodologia: os criodiluidores foram envasados em palhetas de $0,25 \mathrm{~mL}$, distribuídas em hastes de alumínio e congeladas em dry shipper (Cryofarm), por 10 minutos, numa taxa de resfriamento de aproximadamente $25-40^{\circ} \mathrm{C} / \mathrm{min}$, com estabilização gradual de $-181^{\circ} \mathrm{C}$ em $3 \mathrm{~min}$. Em seguida, as hastes de alumínio foram transferidas para um botijão com nitrogênio líquido $\left(-196^{\circ} \mathrm{C}\right)$ e transportadas até o Laboratório de Biotecnologia da Reprodução de Peixes do Núcleo Integrado de Biotecnologia (LBRP-NIB) da UECE (Fortaleza - Ceará). Após uma semana de estocagem, as amostras seminais foram descongeladas em banho-maria a $25^{\circ} \mathrm{C}$ por 30 segundos e analisadas quanto aos parâmetros cinéticos (motilidade total e velocidades espermáticas), à vitalidade e à morfologia espermática. No experimento 2, a análise da duração da motilidade espermática foi acrescentada.

Por meio da análise objetiva computadorizada (CASA), o sêmen foi avaliado quanto aos parâmetros de porcentagem de motilidade total (velocidade espermática $>10 \mu \mathrm{m} / \mathrm{s}$ ), de velocidade curvilinear (VCL), de velocidade em linha reta (VSL) e de velocidade média do percurso (VAP). Cada imagem $(n=25)$ foi analisada utilizando-se a configuração padrão para peixes estabelecida pelo Sperm Class Analyser software $\left(\mathrm{SCA}^{\mathrm{TM}} 2005\right.$, Microptics, S.L., versão 3.2.0, Barcelona, Espanha). Para ativação, $2 \mu \mathrm{L}$ de sêmen foram misturados com $100 \mu \mathrm{L}$ de $\mathrm{NaCl}(0,29 \%)$ em câmara de Makler ${ }^{\circledR}$, e as amostras foram analisadas em microscópio óptico com contraste de fase (Nikon ${ }^{\circledR}$ H550S, ECLIPSE 50i, Japan, 400x) conectado a uma videocâmera. As imagens foram gravadas de três a quatro segundos após a ativação.

A vitalidade espermática foi avaliada de esfregaços corados $(10 \mu \mathrm{L}$ eosina: $10 \mu \mathrm{L}$ nigrosina: $5 \mu \mathrm{L}$ sêmen), contando-se 200 espermatozoides por lâmina em microscópio óptico (400x). Consideraram-se espermatozoides 
vivos com membrana intacta (cabeça não corada) e espermatozoides mortos com ruptura na membrana plasmática (forte coloração avermelhada).

Para a análise morfológica espermática, esfregaços realizados com sêmen fixado em citrato formol $4 \%$ foram corados com rosa bengala, conforme Miliorini et al. (2011), registrando-se os espermatozoides normais (\%) em microscópio óptico (400x). Foram observados 200 espermatozoides $(100$ por lâmina).

A duração da motilidade (segundos) consistiu na observação dos espermatozoides em microscópio óptico (400x; CASA), acionando-se o cronômetro desde o momento da ativação do sêmen até que restassem somente $10 \%$ de células móveis.

No experimento 1, um total de 256 palhetas foram criopreservadas, resultantes da combinação de oito palhetas $x$ quatro tratamentos $\mathrm{x}$ oito pools. Para o experimento 2, foram criopreservadas 384 palhetas, resultantes da combinação de oito palhetas $\mathrm{x}$ seis tratamentos $\mathrm{x}$ oito pools.

Os dados foram inicialmente submetidos aos testes de Shapiro-Wilk e Bartlett para confirmação dos requerimentos, com o objetivo de realização da análise de variância (distribuição normal dos resíduos e homocedasticidade, respectivamente). Nos casos em que não houve homogeneidade de variâncias entre os tratamentos, considerando-se os dados brutos, foram feitas tentativas de transformação (logarítmica, radicial e angular). Para algumas variáveis, a transformação logarítmica resultou em enquadramento nos requerimentos da ANOVA. A análise de variância foi, então, executada, considerando-se um delineamento inteiramente ao acaso, em arranjo fatorial $2 \times 3$, sendo dois tratamentos e três possibilidades de inclusão de vitaminas (vitaminas C, E ou nenhuma vitamina). Nos casos em que houve significância dos efeitos principais ou da interação, foi aplicado o teste de StudentNewman-Keuls (SNK) para comparação das médias. Comparações com o grupo controle foram feitas usando-se o teste de Dunnett. Em alguns casos, persistiu a homocedasticidade, mesmo após as tentativas de transformação, e foi aplicado o teste não paramétrico de KruskalWallis. Em todas as situações, diferenças foram consideradas significativas quando $\mathrm{P}<0,05$, e os resultados foram apresentados como média \pm desvio-padrão.

\section{RESULTADOS}

Para o experimento 1, as amostras do sêmen in natura apresentaram valor médio de motilidade

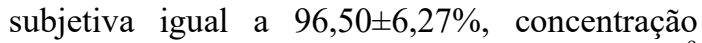
espermática média igual a $19,59 \pm 5,85 \times 10^{9}$ espermatozoides $/ \mathrm{mL}$, volume médio de $7,54 \pm 6,20 \mathrm{~mL}$ e $\mathrm{pH}$ médio de $8,25 \pm 0,26$.

Em todos os tratamentos, independentemente do crioprotetor utilizado e do acréscimo ou não de vitaminas, o sêmen descongelado mostrou uma redução significativa $(\mathrm{P}<0,05)$ em todos os parâmetros seminais avaliados (motilidade total, velocidades, percentual de espermatozoides normais, vitalidade e duração da motilidade) em comparação ao sêmen in natura (Tab.1, 2, 3 e 4).

Quando o sêmen criopreservado com DMSO foi comparado ao $\mathrm{EG}$, os resultados não diferiram entre si $(\mathrm{P}>0,05)$. Contudo, ao serem comparados com o glicerol e o metanol, mostraram motilidade total significativamente superior $(\mathrm{P}<0,05$; Tab. 1). Efeitos deletérios sobre a qualidade seminal foram observados com o glicerol e o metanol com apenas $2 \%$ e $11 \%$ de motilidade total, respectivamente. As velocidades espermáticas do sêmen criopreservado em glicerol e metanol foram abaixo $(\mathrm{P}<0,05)$ dos demais crioprotetores (Tab. 1), quando se observou aglutinação dos espermatozoides logo após a descongelação das amostras com esses dois crioprotetores.

O percentual de espermatozoides normais diminuiu em média $21 \%$ após a criopreservação seminal ao comparar-se com o sêmen in natura (Tab. 2). Apesar do alto percentual de espermatozoides vivos $(\sim 92 \%)$ no grupo controle, apenas cerca de $47 \%$ de espermatozoides foram normais, influenciando negativamente os resultados do sêmen descongelado. Considerando-se como critério principal a motilidade total, seguido da velocidade e da normalidade espermática, os melhores tratamentos em ordem decrescente foram EG, DMSO, metanol e glicerol (Tab. 1 e 2). 


\section{Linhares et al.}

Tabela 1. Efeito de diferentes tipos de crioprotetores sobre os parâmetros cinéticos de espermatozoides frescos (grupo controle) e descongelados de Cyprinus carpio criopreservados em ACP-104 sem vitaminas

\begin{tabular}{c|cccc}
\hline \multirow{2}{*}{ Crioprotetor } & \multicolumn{4}{|c}{ Parâmetros cinéticos } \\
\cline { 2 - 5 } & $\begin{array}{c}\text { Motilidade total } \\
(\%)\end{array}$ & VCL $(\mu \mathrm{m} / \mathrm{s})$ & VSL $(\mu \mathrm{m} / \mathrm{s})$ & VAP $(\mu \mathrm{m} / \mathrm{s})$ \\
\hline Controle & $95,06 \pm 4,34$ & $86,77 \pm 21,27$ & $37,51 \pm 15,09$ & $68,54 \pm 19,70$ \\
DMSO & $24,38 \pm 15,37 * \mathrm{a}$ & $37,68 \pm 3,95 * \mathrm{a}$ & $22,08 \pm 3,76 * \mathrm{a}$ & $31,30 \pm 4,81 * \mathrm{a}$ \\
EG & $28,30 \pm 15,21 * \mathrm{a}$ & $41,70 \pm 5,46 * \mathrm{a}$ & $25,95 \pm 5,19 * \mathrm{a}$ & $36,10 \pm 5,11 * \mathrm{a}$ \\
Glicerol & $2,65 \pm 3,72 * \mathrm{c}$ & $15,39 \pm 16,65 * \mathrm{c}$ & $6,55 \pm 7,22 * \mathrm{c}$ & $11,14 \pm 12,11 * \mathrm{c}$ \\
Metanol & $11,05 \pm 9,48 * \mathrm{~b}$ & $34,50 \pm 4,56 * \mathrm{~b}$ & $17,05 \pm 4,30 * \mathrm{~b}$ & $26,99 \pm 4,73 * \mathrm{~b}$ \\
\hline
\end{tabular}

*Representa diferença significativa em relação ao controle. Letras minúsculas distintas representam diferenças significativas entre linhas. O controle corresponde ao sêmen in natura. ACP-104: água de coco em pó para sêmen de teleósteos de água doce de fertilização externa; DMSO: dimetilsulfóxido; EG: etilenoglicol; VCL: velocidade curvilinear; VSL: velocidade retilinear; VAP: velocidade média do percurso.

Tabela 2. Efeito de diferentes tipos de crioprotetores sobre o percentual de espermatozoides normais e vitalidade de espermatozoides frescos (grupo controle) e descongelados de Cyprinus carpio criopreservados em ACP-104 sem vitaminas

\begin{tabular}{ccc}
\hline Crioprotetor & Espermatozoides normais $(\%)$ & Vitalidade $(\%)$ \\
\hline Controle & $46,62 \pm 13,44$ & $91,75 \pm 3,23$ \\
DMSO & $31,94 \pm 6,97 * \mathrm{a}$ & $37,16 \pm 10,76 * \mathrm{a}$ \\
EG & $26,44 \pm 6,92 * \mathrm{ab}$ & $25,71 \pm 7,39 * \mathrm{~b}$ \\
Glicerol & $20,50 \pm 8,36 * \mathrm{~b}$ & $28,05 \pm 14,78 * \mathrm{ab}$ \\
Metanol & $25,06 \pm 6,79 * \mathrm{ab}$ & $28,09 \pm 8,99 * \mathrm{ab}$ \\
\hline
\end{tabular}

*Representa diferença significativa em relação ao controle. Letras minúsculas distintas representam diferenças significativas entre linhas. O controle corresponde ao sêmen in natura. ACP-104: água de coco em pó para sêmen de teleósteos de água doce de fertilização externa; DMSO: dimetilsulfóxido; EG: etilenoglicol.

Para o segundo experimento, as amostras seminais coletadas apresentaram taxa média de motilidade subjetiva de 90,13 $\pm 22,92 \%$, concentração espermática média de $27,36 \pm 9,83 \times 10^{9}$ espermatozoides/mL, volume médio de $6,65 \pm 6,97 \mathrm{~mL}$ e $\mathrm{pH}$ médio de $7,23 \pm 1,61$.

Os crioprotetores DMSO e EG foram, então, selecionados para o segundo experimento para se avaliar o efeito da suplementação de vitamina C ou E no meio ACP-104 contendo DMSO ou EG sobre a qualidade espermática.

$\mathrm{O}$ acréscimo de vitamina $\mathrm{C}$ ou $\mathrm{E}$ ao $\mathrm{EG}$ não teve nenhum efeito quando comparado ao tratamento sem vitamina ( $>00,05$; Tab. 3). Contudo, a adição de vitamina $\mathrm{C}$ ao DMSO aumentou a taxa de motilidade total em $11 \%$, quando comparada ao tratamento sem vitamina, e em $17 \%$ quando comparada ao tratamento com vitamina $\mathrm{E}$ (Tab. 3). Independentemente do acréscimo ou não de vitaminas, o EG foi o crioprotetor que obteve maiores índices de normalidades espermáticas. Dentro dos tratamentos envolvendo o DMSO, o acréscimo de vitamina C proporcionou maiores índices de normalidade espermática, enquanto o acréscimo de vitamina $\mathrm{E}$ não produziu um efeito benéfico na concentração testada (Tab. 3).

Quanto à vitalidade espermática, o número de células viáveis, após o acréscimo de vitamina $\mathrm{C}$ ou $\mathrm{E}$, foi superior ao tratamento sem vitamina utilizando-se o DMSO como crioprotetor (Tab. 3; $\mathrm{P}<0,05)$. $\mathrm{O}$ uso do $\mathrm{EG}$ acrescido de vitamina $\mathrm{E}$ foi superior quando comparado ao tratamento sem vitamina ou acrescido de vitamina $\mathrm{C}(\mathrm{P}<0,05)$.

O crioprotetor EG foi capaz de manter a duração da motilidade espermática constante, independentemente do acréscimo ou não de vitamina $\mathrm{C}$ ou $\mathrm{E}$ (Tab. 4), não havendo diferença significativa $(\mathrm{P}>0,05)$. 
Tabela 3. Efeito de diferentes tipos de crioprotetores acrescidos de vitaminas sobre os parâmetros de motilidade total (\%), espermatozoides morfologicamente normais (\%) e vitalidade espermática (\%) de espermatozoides frescos (grupo controle) e descongelados de Cyprinus carpio criopreservados em ACP-104

\begin{tabular}{cccccc}
\hline \multirow{2}{*}{$\begin{array}{c}\text { Parâmetros } \\
\text { avaliados }\end{array}$} & Controle & Crioprotetor & \multicolumn{3}{c}{ Vitaminas } \\
\cline { 4 - 6 } & & & Sem vitamina & $\mathrm{C}$ & $\mathrm{E}$ \\
\hline Motilidade total & $96,14 \pm$ & DMSO & $34,63 \pm 6,29 * \mathrm{Bb}$ & $46,04 \pm 9,94 * \mathrm{Aa}$ & $28,87 \pm 7,44 * \mathrm{Bb}$ \\
& 5,89 & EG & $48,22 \pm 9,46 * \mathrm{Aa}$ & $53,93 \pm 12,83 * \mathrm{Aa}$ & $52,50 \pm 15,27 * \mathrm{Aa}$ \\
\hline Espermatozoides & $83,71 \pm$ & DMSO & $32,00 \pm 6,90 * \mathrm{Ab}$ & $40,17 \pm 5,67 * \mathrm{Aa}$ & $21,83 \pm 5,08 * \mathrm{Bc}$ \\
normais & 13,29 & EG & $57,17 \pm 14,85 * \mathrm{Aa}$ & $49,50 \pm 7,48 * \mathrm{Aa}$ & $53,67 \pm 18,29 * \mathrm{Aa}$ \\
\hline Vitalidade & $97,44 \pm$ & DMSO & $47,12 \pm 7,12 * \mathrm{Ba}$ & $67,33 \pm 12,69 * \mathrm{Aa}$ & $74,50 \pm 11,29 * \mathrm{Aa}$ \\
& 2,24 & $\mathrm{EG}$ & $36,75 \pm 7,74 * \mathrm{Bb}$ & $48,58 \pm 8,12 * \mathrm{ABb}$ & $61,08 \pm 22,50 * \mathrm{Aab}$ \\
\hline
\end{tabular}

*Representa diferença significativa em relação ao controle. Letras maiúsculas distintas representam diferenças significativas entre colunas dentro de cada parâmetro analisado (motilidade total, espermatozoides normais e vitalidade). Letras minúsculas distintas representam diferenças significativas entre linhas dentro de cada parâmetro analisado (motilidade total, espermatozoides normais e vitalidade). O controle corresponde ao sêmen in natura. ACP104: água de coco em pó para sêmen de teleósteos de água doce de fertilização externa; DMSO: dimetilsulfóxido; EG: etilenoglicol.

Tabela 4. Efeito de diferentes tipos de crioprotetores acrescidos de vitaminas sobre a duração da motilidade (segundos) de espermatozoides frescos (grupo controle) e descongelados de Cyprinus carpio criopreservados em ACP-104

\begin{tabular}{|c|c|c|c|}
\hline Controle & & $168,14 \pm 55,3$ & \\
\hline \multirow[t]{2}{*}{ Crioprotetor } & \multicolumn{3}{|c|}{ Vitaminas } \\
\hline & Sem vitamina & $\mathrm{C}$ & $\mathrm{E}$ \\
\hline DMSO & $65,57 \pm 10,77 * \mathrm{ABa}$ & $82,37 \pm 25,66^{*} \mathrm{Aa}$ & $50,67 \pm 20,22 * \mathrm{Ba}$ \\
\hline EG & $81,67 \pm 30,60^{*} \mathrm{Aa}$ & $90,83 \pm 9,64 * \mathrm{Aa}$ & $70,54 \pm 11,50 * \mathrm{Aa}$ \\
\hline
\end{tabular}

*Representa diferença significativa em relação ao controle. Letras maiúsculas distintas representam diferenças significativas entre colunas. Letras minúsculas distintas representam diferenças significativas entre linhas. $\mathrm{O}$ controle corresponde ao sêmen in natura. ACP-104: água de coco em pó para sêmen de teleósteos de água doce de fertilização externa; DMSO: dimetilsulfóxido; EG: etilenoglicol.

Foi observado que a duração da motilidade se reduziu em 32 segundos após o acréscimo de vitamina $\mathrm{E}$ ao $\mathrm{DMSO}(50,67 \pm 20,22 \%)$ quando comparada ao tratamento acrescido de vitamina $\mathrm{C}(82,37 \pm 25,66)$, havendo diferença significativa $(\mathrm{P}<0,05)$ entre os dois tratamentos (Tab. 4). No presente estudo, a dose de $0,0001 \mathrm{mg}$ utilizada para a vitamina E combinada com DMSO 10\% não foi benéfica.

\section{DISCUSSÃO}

Este é o primeiro trabalho que avalia a interação do diluente ACP-104 com quatro diferentes crioprotetores na criopreservação do sêmen de carpa comum. Além disso, avalia de forma original o efeito da suplementação de vitamina C ou E ao meio ACP-104 contendo DMSO ou EG.

A redução da qualidade seminal após criopreservação, já observada no sêmen descongelado de várias espécies, vem sendo atribuída principalmente a fatores como estresses osmótico, térmico e oxidativo (Martinez-Páramo et al., 2012). Durante o processo de criopreservação, os espermatozoides são submetidos à diluição do plasma seminal e a temperaturas negativas em curto espaço de tempo. A diluição tem, assim, uma ação multifatorial sobre a resistência dos espermatozoides contra lesões do congelamento (Akçay et al., 2004), que dependem da taxa de diluição e da interação entre a composição química do diluente com o tipo e a concentração de crioprotetor utilizada (Viveiros et al., 2012), produzindo resultados diferenciados em relação à espécie. Além disso, a diluição seminal reduz a concentração de antioxidantes presente no plasma seminal, dificultando o combate aos radicais livres referência. Isso favorece a perda da qualidade seminal devido a danos celulares, tais como alterações na estrutura da bicamada lipídica da membrana espermática, baixa regulação de proteínas de membrana e enzimas 
citoplasmáticas, perda da integridade de membrana e fragmentação de DNA (Li et al., 2010).

Os crioprotetores DMSO e metanol foram utilizados na presente pesquisa por serem comumente utilizados para o sêmen de carpa (Salmito-Vanderley et al., 2014). O EG, ainda pouco utilizado na criopreservação de sêmen da espécie estudada, foi escolhido com base nos estudos de Li et al. (2013), por produzir menos danos osmóticos e oxidativos quando comparado ao DMSO. Embora ambos alterem o estado de fosforilação das proteínas sobre os resíduos de tirosina e treonina (Li et al., 2013), o EG tem sido menos prejudicial a esse efeito (Li et al., 2010; Li et al., 2013). O glicerol é pouco empregado na criopreservação do sêmen de peixes, principalmente na concentração de $10 \%$, pois tem elevada pressão osmótica e viscosidade, o que promove uma aglutinação espermática e injúrias celulares irreversíveis (Irawan et al., 2010). Entretanto, foi escolhido para que fosse investigada a interação entre ele e o diluente ACP-104.

A adição de antioxidantes aos diluidores de criopreservação com o intuito de melhorar a qualidade espermática após a criopreservação vem sendo objeto de estudos por diferentes grupos de pesquisas no mundo (Kutluyer et al., 2014; Navarro et al., 2014). Alguns desses trabalhos têm revelado o efeito positivo de certos antioxidantes tanto sobre a redução dos níveis de ROS e sobre a motilidade total, a qual melhora, quanto na duração da motilidade e na redução das anormalidades espermáticas. Contudo, esse efeito positivo depende do tipo e da concentração do antioxidante (Cao e Cutler, 1997).

As vitaminas $\mathrm{C}$ e $\mathrm{E}$ são conhecidas como potentes antioxidantes, capazes de eliminar os radicais livres e seus efeitos negativos. A vitamina $\mathrm{C}$ interage com a vitamina $\mathrm{E}$ e com o selênio na manutenção da atividade de algumas enzimas, como a superóxido dismutase (SOD) e a glutationa peroxidase, que são importantes para a eliminação de radicais oxidantes produzidos pelo metabolismo espermático (Navarro et al., 2009). Entretanto, a interação da vitamina C com $\mathrm{E}$, juntamente com o ACP-104, não foi investigada no presente estudo.
A água de coco verde, que é base para o diluente ACP-104, é rica em aminoácidos, vitaminas, sais minerais, carboidratos, além de possuir baixo teor de lipídios saturados e insaturados (Carvalho et al., 2006). A vitamina $\mathrm{C}$, presente no coco verde, é capaz de proporcionar uma ação antiinflamatória e antioxidante ao eliminar diretamente os radicais livres e inibir a produção in vitro de substâncias reativas ao ácido tiobarbitúrico (TBARS) (Carvalho et al., 2006; Santos et al., 2013), destacando-se assim, a importância da água de coco como uma alternativa no combate as ROS.

O processo de liofilização da água de coco reduz drasticamente os níveis de seus compostos, muito embora a concentração de ácido ascórbico se mantenha constante, segundo Santos et al. (2013). No produto ACP, após a liofilização, detectaram-se, para cada $100 \mathrm{~g}$ do pó, $16,51 \mathrm{mg}$ de vitamina C (Carvalho, 2013). Todavia, o volume de diluente ACP, utilizado neste estudo, continha apenas $0,034 \mathrm{mg}$ de vitamina $\mathrm{C}$ para cada $\mathrm{mL}$ de sêmen criopreservado, sugerindo-se que a concentração de ácido ascórbico, tanto do diluente quanto da suplementação, pode ter sido insuficiente para atuar na eliminação das ROS. Desse modo, é necessário investigar concentrações mais elevadas de vitaminas $\mathrm{C}$ e $\mathrm{E}$ e suas interações com outros antioxidantes na suplementação do meio ACP-104, capazes de favorecer um aumento significativo na qualidade do sêmen pós-descongelado que seja comparável ao sêmen fresco.

Outro ponto a ser levado em consideração é o estresse que os peixes podem ter sofrido durante o período de estiagem que assola a região onde foram realizados os experimentos (CPAq, DNOCS - Pentecoste - CE). A crise hídrica vem diminuindo a níveis críticos a água dos reservatórios (Calendário..., 2015), o que pode ser um dos fatores que provocam alterações na qualidade de água (Linhares et al., 2013) e na maturação dos gametas, justificando as baixas taxas de velocidades dos espermatozoides e o alto percentual de anormalidades espermáticas encontrados na pesquisa. Apesar disso, a morfologia dos espermatozoides está dentro dos padrões de normalidade exigidos para outros animais pelo Colégio Brasileiro de Reprodução Animal (Manual..., 2013). 
A duração da motilidade espermática é considerada um parâmetro importante a ser avaliado, pois os espermatozoides necessitam de um tempo para encontrar a micrópila do ovócito e fertilizá-la. Na presente pesquisa, o EG livre ou não de vitaminas e o DMSO adicionado à vitamina $\mathrm{C}$ foram os tratamentos que apresentaram duração de motilidade suficiente para os espermatozoides encontrarem a micrópila.

\section{CONCLUSÃO}

Conclui-se que o EG suplementado ou não com vitamina E é o crioprotetor de escolha a ser utilizado com o meio ACP-104 para criopreservar espermatozoides de carpa, por apresentar melhor desempenho em termos de motilidade, de normalidade, de vitalidade e de duração da motilidade espermática.

\section{REFERÊNCIAS}

AKÇAY, E.; BOZKURT, Y.; SEÇER, S.; TEKÜN, N. Cryopreservation of mirror carp semen. Turk. J. Vet. Anim. Sci., v.28, p.837-843, 2004.

CALENDÁRIO das chuvas no estado do Ceará. [Fortaleza]: FUNCEME, 2015. Disponível em: $<$ http://www.funceme.br/app/calendario/produto/ municipios/maxima/diario $>$. Acessado em: 1 jun. 2015.

CAO, G.; CUTLER, R.G. High concentration of antioxidants may not improve defense against oxidative stress. Arch. Gerontol. Geriatr., v.17, p.189-201, 1997.

CARVALHO, J.M.; MAIA, G.A.; SOUSA, P.H.M.; MAIA JR., G.A. Água-de-coco: Propriedades nutricionais, funcionais e processamento. Semin. Cienc. Agrar., v.27, p.437-452, 2006.

CARVALHO, M.A.M. Água de coco em pó na criopreservação do sêmen de carpa comum, Cyprinus carpio L. 2013. 123f. Tese (Doutorado em Biotecnologia) - Rede Nordeste de Biotecnologia, Universidade Estadual do Ceará, Fortaleza, CE.
CARVALHO, M.A.M.; LINHARES, F.R.A.; NUNES, J.F. et al. Água de coco como diluente para o sêmen de peixes de água doce de fertilização externa. Rev. Bras. Hig. Sanit. Anim., v.8, p.203-222, 2014.

CARVALHO, O.F.; FERREIRA, J.D.J.; SILVEIRA, N.A.; FRENEAU, G.E. Efeito oxidativo do óxido nítrico e infertilidade no macho. J. Bras. Patol. Med. Lab., v.38, p.33-38, 2002.

IRAWAN, H.; VUTHIPHANDCHAI, V.; NIMRAT, S. The effect of extenders, cryoprotectants and cryopreservation methods on common carp (Cyprinus carpio) sperm. Anim. Reprod. Sci., v.122, p.236-243, 2010.

KUTLUYER, F.; KAYIM, M.; ÖĞRETMEN, F. et al. Cryopreservation of rainbow trout Oncorhynchus mykiss spermatozoa: Effects of extender supplemented with different antioxidants on sperm motility, velocity and fertility. Cryobiology, v.69, p.462-466, 2014.

LAHNSTEINER, F.; MANSOUR, N. A comparative study on antioxidant systems in semen of species of the percidae, salmonidae, cyprinidae, and lotidae for improving semen storage techniques. Aquaculture, v.307, p.130140, 2010.

LI, P.; HULAK, M.; LI, Z.H. et al. Cryopreservation of common carp (Cyprinus carpio L.) sperm induces protein phosphorylation in tyrosine and threonine residues. Theriogenology, v.80, p.84-89, 2013.

LI, P.; LI, Z.H.; DZYUBA, B. et al. Evaluating the impacts of osmotic and oxidative stress on common carp (Cyprinus carpio, L.) sperm caused by cryopreservation techniques. Biol. Reprod., v.83, p.852-858, 2010.

LINHARES, F.R.A.; NUNES, L.T.; LOPES, J.T. et al. Influência da qualidade da água sobre o desenvolvimento embrionário de carpa comum (Cyprinus carpio). Ciênc. Anim., v.23, p.29-35, 2013.

LINHARES, F.R.A.; SALMITO-VANDERLEY, C.S.B.; CARVALHO, M.A.M. et al. Cinética e morfologia de espermatozoides de carpa comum criopreservados em água de coco em pó ACP-104. Arq. Bras. Med. Vet. Zootec., v.67, p.1313-1320, 2015. 
MANUAL para exames andrológicos e avaliação de sêmen animal. 3.ed. Belo Horizonte: CBRA, 2013. 104p.

MARTINEZ-PÁRAMO, S.; DIOGO, P.; DINIS, M.T. et al. Incorporation of ascorbic acid and $\alpha$-tocopherol to the extender media to enhance antioxidant system of cryopreserved sea bass sperm. Theriogenology, v.77, p.1129-1136, 2012.

MILIORINI, A.B.; MURGAS, L.D.S.; ROSA, P.V. et al. A morphological classification proposal for curimba (Prochilodus lineatus) sperm damages after cryopreservation. Aquacult. Res., v.42, p.177-187, 2011.

NAVARRO, R.D.; NAVARRO, F.K.S.P.; FELIZARDO, V.O. et al. Semen quality of curimba (Prochilodus lineatus) cryopreserved with vitamins. Acta Sci. Technol., v.36, p.55-60, 2014.

NAVARRO, R.D.; RIBEIRO FILHO, O.P.; FERREIRA, W.M.; PEREIRA, F.K.S. A importância da vitamina E, C e A na reprodução de peixes. Rev. Bras. Reprod. Anim., v.33, p.20-25, 2009.
SALMITO-VANDERLEY, C.S.B.; LINHARES, F.R.A.; CARVALHO, M.A.M. et al. Biotécnicas aplicadas a reprodução de ciprinídeos. Acta Vet. Bras., v.8, Supl.2, p.292-298, 2014.

SANTOS, J.L.A.; BISPO, V.S.; FILHO, A.B.C. et al. Evaluation of chemical constituents and antioxidant activity of coconut water (Cocus nucifera L.) and caffeic acid in cell culture. $A n$. Acad. Bras. Cienc., v.85, p.1235-1246, 2013.

SŁOWIŃSKA, M.; NYNCA, J.; CEJKO, B.I. et al. Total antioxidant capacity of fish seminal plasma. Aquaculture, v.400-401, p.101-104, 2013.

VIVEIROS, A.T.M.; ORFÃO, L.H.; NASCIMENTO, A.F. et al. Effects of extenders, cryoprotectants and freezing methods on sperm quality of the threatened Brazilian freshwater fish pirapitingado-sul Brycon opalinus (Characiformes). Theriogenology, v.78, p.361-368, 2012. 